\title{
The Effects of News Bias-Induced Anger, Anxiety, and Issue Novelty on Subsequent News Preferences
}

\author{
Yi-Hsing Han ${ }^{1 *}$, Laura Arpan ${ }^{2}$ \\ ${ }^{1}$ Department of Journalism \& Communication Studies, Fu Jen Catholic University, Taiwan \\ ${ }^{2}$ School of Communication, Florida State University, Tallahassee, FL, USA \\ Email: ^134880@mail.fju.edu.tw
}

How to cite this paper: Han, Y.-H., \& Arpan, L. (2017). The Effects of News Bias-Induced Anger, Anxiety, and Issue Novelty on Subsequent News Preferences. Advances in Journalism and Communication, 5, 256-277.

https://doi.org/10.4236/ajc.2017.54015

Received: September 10, 2017

Accepted: December 23, 2017

Published: December 26, 2017

Copyright $\odot 2017$ by authors and Scientific Research Publishing Inc. This work is licensed under the Creative Commons Attribution International License (CC BY 4.0).

http://creativecommons.org/licenses/by/4.0/

\section{cc) (i) Open Access}

\begin{abstract}
Research has established that political partisans' emotional responses to identity-threatening information can affect their subsequent information preferences. Based on the hostile media effect and the cognitive motivational-relational theory of emotion, we examined the influence of emotions stimulated by perceptions of news bias on information seeking preferences, as well as the role of issue novelty. An experiment with a 2 (Novel vs. Familiar issues) $\times 2$ (Threatening news stories vs. Non-threatening/control news story) design explored mediating effects of anger and anxiety on subsequent information preferences (identity-bolstering information and identity-threatening information), as well as moderating effects of issue novelty. Bias-induced anger, but not anxiety, motivated participants to want to read additional identity-threatening information. Perceived issue novelty elicited greater anger and enhanced bias-induced anger's effects on identity-threatening information preferences. The findings have implications for the relationship between exposure to identity-threatening news and selective exposure in a democratic society.
\end{abstract}

\section{Keywords}

News Preferences, Emotion, Information Seeking, Bias, Novelty

\section{Introduction}

News media consumption has been on the decline for the past three decades (Pew Research Center, 2012a). Additionally, evidence suggests that audience members who perceive news content as lacking in credibility might consume less of it or seek content from nonmainstream or more ideologically focused sources they 
perceive as sharing their point of view (Pew Research Center, 2006, 2012b; Tsfati \& Capella, 2003). Both less consumption of news content and selective exposure (e.g., the avoidance of counter-attitudinal information) present challenges to modern democracy-there will potentially be more less-informed and more polarized citizens (Bennett \& Iyengar, 2008). The hostile media effect (HME) describes the tendency for audiences to perceive news coverage of an issue with which they are highly involved as biased (Gunther \& Liebhart, 2006; Huge \& Glynn, 2010), making it difficult to achieve a non-biased perception of any story addressing a contentious issue. Therefore, a more polarized society may trigger more subsequent selective exposure.

The internet and other new technologies have the potential to exacerbate selective exposure tendencies and to threaten the marketplace of ideas and democracy (Bennett \& Iyengar, 2008, 2010; Holbert, Garrett, \& Gleason, 2010). For example, bloggers choose attitudinally consistent blogs, and both bloggers and their readers are characterized by ideological homogeneity (Bennett \& Iyengar, 2008; Lawrence, Sides, \& Farrell, 2010). Such selective exposure may not only be harmful to democracy but also may cause potential political disengagement.

However, it appears to be too soon to conclude that political partisans' biased perceptions will lead to subsequent biased (selective) exposure. Recent studies show evidence that partisans' selective exposure contributes to political polarization, but provide limited evidence that political polarization contributes to congenial media exposure (Stroud, 2011). Additionally, research based on an effective approach has identified possible factors that might mediate the influence of new bias perceptions on selective exposure. Bias-induced, discrete emotions (particularly anger and anxiety) may drive audience members to seek both pro- and counter-attitudinal information and have been proposed as alternative explanations for congenial information preferences (Arpan \& Nabi, 2011; Hwang et al., 2008; Valentino et al., 2008). Therefore, we examined the mediating role of these two discrete emotions on information seeking that occurred after exposure to news content perceived as biased.

Additionally, although research on selective exposure has found that people have a preference for pro-attitudinal over counter-attitudinal information (for a review, see Smith, Fabrigar, \& Norris, 2008), a unique feature of news is novelty. Perceived familiarity with an issue is often associated with attitudes and opinions related to that issue (Han, Chock, \& Shoemaker, 2009), and issue familiarity can impact intention to seek additional information (Sawicki et al., 2011): familiar, pro-attitudinal information may not strengthen confidence in one's existing attitudes. On the contrary, less familiar, pro-attitudinal information may give new support that helps to bolster existing attitudes. Accordingly, we also investigated the moderating influence of issue novelty on information preferences after exposure to news perceived as biased.

\section{Literature Review}

Research on the hostile media effect finds that audience members' involvement 
with an issue or group reliably determines their perceptions of whether news coverage is credible or biased (Gunther, 1998; Gunther \& Schmitt, 2004; Lee, 2010). Biased perception is defined as any form of perceived preferential and unbalanced treatment, or favoritism, toward a social group (Gunther, 1998). Partisanship or group membership is the key driver of the HME. Social identity theory explains that people tend to self-categorize and define themselves based on their associations with various social groups, for example, political parties, organizations, religious groups, age cohort, and ethnic groups (Tajfel \& Turner, 1985) and suggests that people may consider identity-bolstering information approvable and accept it as in-group information. The acceptance of information favorable to one's identity is consistent with biased assimilation-people tend to accept confirming information at face value (Lord, Ross, \& Lepper, 1979). However, categorization based on social identity theory suggests not only biased assimilation, but also a "contrast" effect-people tend to subject disconfirming information to a more critical evaluation (Lord, Ross, \& Lepper, 1979). Accordingly, news content containing any information critical of one's group is likely to be rejected, criticized (evaluated as "biased"), or subjected to relatively high levels of scrutiny.

\subsection{The Role of Emotion}

Research based upon the cognitive tradition has suggested that partisans' biased perceptions of news stories about controversial issues involving their group are inevitable, and partisans may seek more like-minded media content to avoid exposing themselves to psychological discomfort associated with exposure to "biased" information. However, individuals' claims of news bias might indicate a particular emotional response. Emotions have been defined as "a set of physiological and psychological changes within the body and brain which come as a response to external, situational stimuli" (Kiss, 2012: p. 7). Emotions are organisms' adaptive response, often functioning as a defense mechanism (Marcus, 2002; Kiss, 2012), and have the capacity to influence our behavior (Damasio, 1994; Lazarus, 1991; LeDoux, 1996; Kiss, 2012). For example, media indignation, conceptualized as a form of anger, was found to have a positive association with willingness to participate in discursive activities (e.g., attend a public forum, let one's opinion be posted on the webpage of an organization, look for more information on the issue, talk about the issue with others who have opposing or similar views). Such willingness implies that, after exposure to news perceived as biased, experienced anger might influence people to seek both pro- and counter-attitudinal information to prepare for future discussion and action.

Research examining the relationship between partisans' emotional state and subsequent responses has identified a moderating effect of emotion on the influence of exposure to counter-attitudinal or threatening content on subsequent information preferences (Arpan \& Nabi, 2011; Valentino et al., 2008; Matthes, 2011). Additionally, research on responses to political campaign advertisements 
has identified a relationship between emotions such as anxiety and subsequent information seeking or political participation (e.g., Brader, Valentino, \& Suhay, 2004; Valentino, Hutchings, Banks, \& Davis, 2008; Brader, Valentino, \& Suhay, 2008; Valentino, Banks, Hutchings, \& Davis, 2009; Kiss, 2012). These studies provide evidence that emotion can play a role in partisans' subsequent information preferences. However, there are conflicting propositions regarding how anger and anxiety influence relevant outcomes.

According to Affective Intelligence Theory (AIT) (Marcus, Neuman, \& MacKuen, 2000), when partisans are surprised or have an unexpected experience, anxiety is the most frequently experienced emotion. In particular, when partisans perceive threat cues in the news about their identity (e.g., a political party with which they identify), anxiety will be triggered, which can "produce changes in opinion and behavior independent of changes in beliefs about the severity of the issue or problem" (Brader et al., 2008: p. 3). Marcus (2002) argued that it is the experience of anxiety that makes partisans depart from their party identification preference (minimizing reliance on the dispositional system/habit). Therefore, when exposed to threatening information the resulting anxiety boosts information seeking (activates the surveillance system) either to reduce uncertainty by reassuring their party identification preference or to facilitate a change in preferences. In short, anxiety influences partisans' judgments indirectly by weakening partisans' tendency toward habits (e.g., voting, information seeking preference) and redirecting partisans to be more attentive to contemporary information (Brader, 2011).

However, such propositions and studies may have over-emphasized the influence of anxiety on subsequent responses (e.g., preference based on party identification) and under-emphasized the role of anger, which is often confounded with anxiety in studies of AIT (Ladd \& Lenz, 2008). In addition, when assessing the effect of anger, one study (Marcus et al., 2000) used a similar dimension, aversion, rather than discrete anger to explore possible effects on political behaviors. However, aversion is a rather broad construct. For example, in another study (MacKuen, Wolak, Keele, \& Marcus, 2010) the construct of aversion included measures of anger, contempt, disgust, and bitterness, but discrete emotions, such as anger and disgust, might have quite different effects and origins (Lazarus, 1991). Nevertheless, some suggest anxiety is beneficial to democracy, and aversion is detrimental to deliberation, because it will reduce motivation to seek more information in order to avoid more exposure to threatening or distasteful information (MacKuen et al., 2010).

Similarly Valentino, Hutchings, Banks, and Davis (2008) argued that although anxiety will boost further information seeking to confirm the novel, threatening stimuli (e.g., seeking more information to either reassure one's own view or to gather information for the possibility of changing it), anger will close off the information search and induce a higher reliance on habit. Based on experimental research tracking participants' information search behavior in a web-based environ- 
ment, MacKuen et al. (2010) found that anxiety induced by counter-attitudinal information promoted more consideration of opposing views (i.e., searching for additional challenging information and future intent to search for challenging information), but aversion that was induced by the same stimuli was associated with less consideration of opposing views.

However, more recent studies have suggested an alternative approach to understanding emotions in this context (Arpan \& Nabi, 2011; Groenendyk, 2011), relying upon an appraisal theory of emotions (Lazarus, 1991). This approach suggests anger is likely to increase, rather than decrease interest in additional, relevant information-both threatening and non-threatening. For example, it suggests that the induction of anger is related to the attribution of blaming others, such as partisans blaming the news media for "biased" news stories about their social groups-a typical HME case-and emphasizes the "approach" action tendency of anger. Accordingly, anger should increase, rather than suppress, subsequent information seeking.

Lazarus's (1991) cognitive motivational-relational theory of emotion (CMRT) identifies unique (discrete) emotions and predicts both their onset and outcomes or action tendencies (Nabi, 2010). Specifically, CMRT provides clear patterns of appraisal for anger and anxiety (Brader \& Valentino, 2007; Huddy, Feldman, \& Cassese, 2007; Isbell, Ottati, \& Burns, 2006; Steenbergen \& Ellis, 2006). Anger is felt when one perceives "a demeaning offense against me and mine", or experiences an offense that is deemed "arbitrary, inconsiderate, or malevolent contributes to the impression that we have been demeaned" (Lazarus, 1991: p. 222). The angry person has suffered perceived damage or threat to ego-identity, whether or not this is recognized or acknowledged.

A critical appraisal component for anger is blame, which is dependent on whether someone can be held accountable for the damage or threat (Lazarus, 1991). In contrast to fright and anxiety, anger is best addressed by attack, which is the innate action tendency when an individual considers retaliation favorably (Lazarus, 1991). In other words, "blame" is the key appraisal component of anger, and the response is approach-oriented. Conversely, for anxiety, the threat is not a demeaning offense but uncertainty and the potential loss of meaning, which makes one feel somewhat powerless; there is no obvious agent of threat, and so there is no blame in anxiety (Lazarus, 1991). Anxiety itself does not always have a clear directional action tendency because it is often accompanied by either anger or fear.

Although work guided by AIT has suggested that anger discourages partisans' relevant information seeking (e.g., Marcus et al., 2000; Huddy, Feldman, \& Cassese, 2007; Valentino et al., 2008) others have argued and found that the approach action tendency of anger can encourage partisans' information seeking for the purpose of future debate, assessing the nature and extent of negative information about the group, defending existing views (e.g., Hwang et al., 2008; Arpan \& Nabi, 2011; Matthes, 2011), and/or or to be ready to discuss issues with 
non-likeminded others (Mutz, 2006).

These conflicting propositions and findings regarding anger are not surprising for at least five reasons: induction of anger based on different contexts, different rationales for the role of information seeking to fill the gap between anger and subsequent behaviors (e.g., voting, discursive activities), different measures of assessing information seeking (e.g., length of time spent on viewing information, breadth of information seeking, information preference and information valence), and theoretical claims about the causal relationship between discrete emotions and subsequent behavior (Han, 2014).

Considering CMRT together with the more cognitive predictors and outcomes in previous HME studies leads us to predict the effect of anger when one perceives a news story to be biased against her/him. Based on CMRT, those who feel anger after reading a news story perceived as bias should seek out the responsible agent to blame, and, according to the HME, news media are often the accused agents when partisans consider stories as widely disseminated (Gunther \& Liebhart, 2006). Therefore, when partisans perceive bias in news content the action tendency of bias-induced anger should lead them to criticize news media for disseminating biased news content and to seek out additional relevant information in order to defend their existing views (Arpan \& Nabi, 2011). Therefore, in an attempt to reconcile previous conflicting propositions and findings with respect to the influence of anger and anxiety on subsequent information preferences, we concurrently examined the influence of both discrete emotions on information preferences following exposure to threatening news content (content perceived as biased against one's group).

\subsection{Issue Novelty}

Additionally, we consider a message factor that could moderate the effects of bias-induced emotion on subsequent information preferences: novelty. People often survey their environment for things that are deviant or unusual because they might pose potential threats; therefore, this need determines both the existence of the news media and the shape that news often takes (Shoemaker, 1996). Although novelty seems to be the nature of news, often we are quite familiar with some issues in daily news. Partisans may find that, for most conflicting issues, it is not difficult for them to guess the other side's arguments. However, the news media do not miss the truly novel, and people tend to pay more attention to these "new" issues because of a basic need for surveillance.

Information familiarity could impact the desirability of pro-attitudinal information for a number of reasons. For example, familiar and unfamiliar information may not be equally capable of meeting the goals present at information selection time (e.g., bolstering, avoiding threat, refuting the opposition) (Sawicki et al., 2011). Well-known, agreeable information might not significantly increase confidence in an existing attitude. Further, while "familiar but disagreeable information may be undesirable because it has been encountered and deemed 
invalid, unfamiliar disagreeable information might be counter-argued" (Sawicki et al., 2011: p. 543). Therefore, the familiar threat may be considered less threatening, and the relatively new threat may be perceived as more threatening. Nabi (2002) also found that anger arousal might prompt closer information processing for an unfamiliar topic and under conditions of uncertainty regarding message content. Accordingly, novelty could impact emotional responses and influence preferences following exposure to news content perceived as biased.

\section{Summary, Purpose, and Hypotheses}

Two main purposes guided our examination of bias-induced, discrete emotions on subsequent information preference. First, we investigated the mediating effect of bias-induced anger and anxiety on subsequent information preferences to attempt to clarify the conflicting propositions and previous findings. Second, we examined whether issue novelty moderated the proposed effects of partisans' perceived bias and emotional responses in order to further examine the role of surveillance and reassurance needs in emotion-influenced information preferences.

As discussed, the action tendency of anger is to retaliate, whereas the action tendency of anxiety is to protect (Lazarus, 1991). Although retaliation suggests a preference for negative information for finding fault and attack, protection implies both restoration of identity and refutation of false accusations. Thus, anger might trigger stronger motivation to view additional counter-attitudinal information than anxiety. A reasonable approach to distinguish the effects between anger and anxiety on information preferences is to provide threatening information followed by options for additional identity-threatening information as well as identity-bolstering information. This valence-based information preference investigation is consistent with the logic of the distinct action tendencies of anger and anxiety.

Partisans may experience anger and anxiety after they perceive bias in a news story that includes information that is threatening to their group, and therefore, their identity (Arpan \& Nabi, 2011; Hwang et al, 2008; Valentino et al, 2008). Bias-induced anger is generated because partisans consider the story biased against their group and also because they blame news media for the unfair coverage. Bias-induced anxiety may be aroused because one's existing view or affiliation is challenged and more information is needed to reduce the uncertainty-to restore identity or to be ready to change group affiliation. Therefore, we hypothesized that partisans would feel anger and anxiety after reading an identity-threatening news story because of perceived bias, compared to those who read a neutral news story. Therefore,

H1: Participants who read an identity-threatening news article will feel more anger and anxiety than those who read a neutral news article.

H2a-b: Among those who read an identity-threatening news article, perceived bias will be positively correlated with the level of (a) anger and (b) 
anxiety reported by participants.

Based on AIT, we predict exposure to identity-threatening news content will induce anxiety, which should motivate partisans to seek out more identity-threatening and identity-bolstering information for protecting their identity and reducing uncertainty. Based on CMRT, we predict exposure to identity-threatening news content will also induce anger, which should motivate partisans to seek out both identity-bolstering and identity-threatening information to restore their identity, assess the damage, and/or refute criticism. In short, the threat to identity and resulting emotional responses should enhance preferences for both types of information.

H3a-b: Participants who read an identity-threatening news article will have more desire to read both (a) additional identity-bolstering news content and (b) additional identity-threatening news content than those who read a neutral news article.

Finally, we predict that the outcomes specified in $H 3$ will be a function of the extent of anxiety and anger experienced after reading threatening news content (content perceived as biased). Because of the above-described conflicting predictions about the mediating influence of anger and anxiety on subsequent information preferences, we posed the following research question:

RQ1: Among those who read identity-threatening news stories, do anger and anxiety both mediate the effect of participants' perceived bias on their subsequent information preferences (interest in both identity-threatening information and identity-bolstering information)?

As described above, familiar information could be considered less threatening, resulting in weaker emotional responses, while the relatively new threat may be considered more threatening, resulting in stronger emotional responses. Therefore, exposure to novel, identity-threatening information should induce more perceived bias. The novel, identity-threatening issue may also induce higher levels of anger and anxiety than the familiar, identity-threatening issue.

H4a: Identity-threatening news stories describing novel issues will generate greater perceptions of bias than identity-threatening stories describing familiar issues.

H4b-c. Identity-threatening news stories describing novel issues will generate more (b) anger and (c) anxiety than identity-threatening stories describing familiar issues.

In addition, this moderating effect of perceived novelty on anger and anxiety may indirectly affect subsequent information preferences. Therefore, RQ2: Does perceived novelty moderate the mediating effects of bias-induced anger and bias-induced anxiety on subsequent information preferences (both identity-threatening information and identity-bolstering information)? 


\section{Method}

\section{Design, Procedure, and Stimulus Materials}

Participants, who received extra course credit, were recruited from undergraduate courses at a research university in the United States. An experiment with a 2 (Novel vs. Familiar issues) $\times 2$ (Identity threatening news stories vs. Nonthreatening/control news story) design manipulated across seven existing news stories was employed. Participants were randomly assigned to one of these seven news story conditions. The experiment was conducted in laboratory facilities at the university. The order of tasks was: exposure to one news article then completion of a questionnaire including emotional responses, perceived novelty, perceived bias, subsequent news preferences, and demographic questions. Participants were then debriefed and dismissed. The entire procedure required 25 to 30 minutes.

This study employed six news stories intended to be perceived as identity-threatening to the college-student participants (whom we considered partisans with respect to the news topic): three about novel issues and three about familiar issues (relative novelty of stories was verified in a pilot study with the same sample pool). ${ }^{1}$ The six news stories were previously published in USA $T O D A Y$ and were quite similar in writing style and at the same literacy level. They included stories about college students lacking empathy, showing a lack of concern for the poor, not working hard enough in school/having poor graduation rates, being binge drinkers, showing no significant gains in learning in college, and being overweight because of unhealthy eating. The first three were intended to be novel stories; the latter three were intended to be familiar. Participants in the control group read a story about how college libraries have become digitized.

\section{Measurement}

Perceived Novelty was measured with four items adapted from an existing scale (Anthony et al., 2004): the information made me think about the bigger issue in a different way, is new to me, introduced a novel perspective to my views about college students, and offered me novel experiences. Response options ranged from extremely (10) and not at all (0). Higher scores indicate greater perceived novelty, $M=5.44, S D=2.09, \alpha=.80$.

\footnotetext{
${ }^{1}$ In the pilot test, an independent-samples $t$ test, $t(85)=3.26, p<.001$, found those who read novel issue news stories, $M=7.45, S D=3.30$, rated them as higher in perceived novelty than those who read familiar issue news stories, $M=5.16, S D=3.16$. However, in the experiment, an ANOVA with Tukey HSD post hoc analysis indicated that one article intended to be perceived as reporting a familiar issue (the story about how, after the first two years of college, students show small gains) was perceived similarly as the three articles intended to be perceived as reporting a novel issue, $M=$ $6.34, S D=1.56$. Therefore, we pooled the three articles rated as novel with this article, resulting in a 4 (novel) X 2 (familiar) design for issue novelty. After that, an independent-samples $t$ test, $t(207)=$ $7.82, p<.001$, indicated those who read stories intended to be perceived as reporting novel issues, $M=6.20, S D=2.00$, rated them as higher in perceived novelty than those who read stories intended to be perceived as reporting familiar issues, $M=3.99, S D=1.74$.
} 
Perceived Bias was measured with three items adapted from Schmitt et al. (2004): the portrayal of COLLEGE STUDENTS in this article was biased against them, the reporter responsible for this article was biased against COLLEGE STUDENTS, and what percentage of the news story was unfavorable to the COLLEGESTUDENTS. Response options for first two ranged from not at all (0) to extremely (10). Response options for the third item were in ten percent increments $(0 \%-100 \%)$ and were recoded to $0-10$, with 0 representing $0 \%$ and $10 \%$ representing $100 \%$. Higher scores indicate greater perceived bias, $M=5.55$, $S D=2.67, \alpha=.84$.

Emotional Responses. Participants were asked how they felt after reading the stories and rated each feeling in a 22 -item list, adapted from Clark et al. (1994). Seven-point Likert-type response categories were used ("not at all" to "extreme$\left.1 y^{\prime \prime}\right)$. Anger was measured with four items: irritated, angry, aggravated, and furious, $M=1.57, S D=1.09, \alpha=.81$. Anxiety was measured with four items: nervous, anxious, tense, and worried, $M=1.92, S D=1.32, \alpha=.80$.

Subsequent Information Preference was assessed via items that asked participants about their interest in reading additional articles designed to serve as identity-bolstering toward college students (e.g., "More young people take the time to help others than ever before.") and identity-threatening toward college students (e.g., "At least half of all college students admit to cheating."). Another three news articles were used as distractors (e.g., "Student programs at risk because of budget shortfalls."). Each headline accompanied by a short lead was shown to each participant in a randomized order. After participants read the headlines/leads, they were asked, "How interested are you in reading it?" Response categories ranged from $0 \%$ (not at all) to $100 \%$ (extremely). A pilot study was conducted to ensure that each headline was perceived as intended (identitythreatening vs. identity-bolstering).

\section{Results}

A total of 243 (77\% females) completed the entire study. Most participants identified as White/Caucasian (68.7\%), followed by Hispanic (18.1\%), African American (7\%), Asian (2.9\%), and other (3.3\%); ages ranged from 18 to 23 years old with a mean of 20.23, $S D$ of 1.58 .

$\mathrm{H} 1$ predicted that participants who read an identity-threatening news article would feel more anger and anxiety than those who read a neutral news article. For the test of H1, we pooled all six identity-threatening news article conditions, and thus created two contrasting groups: those who read an identity-threatening news article (regardless of whether it described new or familiar issues) versus those who read a neutral news article. Two independent-samples $t$ tests were conducted with two dependent variables: anger and anxiety.

Those assigned to read an identity-threatening news article $(M=1.62, S D$ $=.94)$ felt more anger than those assigned to read a neutral news article $(M=$ $1.21, S D=.45), t(88.44)=4.10, p<.001$, Cohen's $d=.56$. Additionally, those 
who read an identity-threatening news article $(M=1.98, S D=1.07)$ felt more anxiety than those who read a neutral news article $(M=1.60, S D=.92), t(241)=$ 1.93, $p<.05$, Cohen's $d=.38$ (one-tailed test). Therefore, H1 was supported.

Based on Lazarus' (1991) cognitive theory of emotion, which has suggested that emotion is a response to meaning and may influence subsequent cognitions and emotions, we assumed that bias perceptions occurred prior to emotional responses, although there might be a reciprocal relationship between appraisal of threats (i.e., perceived bias in the story) and those negative emotional responses. Before testing $\mathrm{H} 2$, the assumption that those who read identity-threatening news articles perceived more bias than those who read neutral news article should be established. An independent-samples $t$ test indicated that those who read an identity-threatening news article $(M=5.82, S D=2.27)$ did perceive more bias than those who read a neutral news article $(M=3.86, S D=1.92), t(241)=4.77$, $p<.001$, Cohen's $d=.93$.

For the tests of $\mathrm{H} 2 \mathrm{a}$ and $\mathrm{H} 2 \mathrm{~b}$, a Pearson's $r$ was calculated with only responses from those assigned to read identity-threatening news articles. The results indicated that both anger $(r=.13, p<.05)$ and anxiety $(r=.16, p<.05)$ were positively correlated with perceived bias. Therefore, $\mathrm{H} 2 \mathrm{a}$ and $\mathrm{H} 2 \mathrm{~b}$ were supported.

For comparison, we also investigated the relationship between anger, anxiety, and perceived bias among those who read the neutral/control news article. Discrete emotions were not correlated with perceived bias in this control group. Therefore, this comparison brought out a sharp contrast between the emotional responses in identity-threatening condition and those in the neutral condition. In short, while the identity-threatening news articles did elicit bias perceptions that were correlated with negative emotions, no association between perceived bias and these negative emotions (Anger: $r=-.26, p=.14$; Anxiety: $r=-.01, p$ $=.96$ ) was found among those who read a neutral/control news article.

$\mathrm{H} 3 \mathrm{a}-\mathrm{b}$ predicted that exposure to identity-threatening news articles would motivate individuals to seek more both additional identity-bolstering news excerpts and additional identity-threatening news excerpts than would exposure to the neutral news article. The dependent variable of additional information seeking was comprised of two measurements: motivation to read additional identity-bolstering information and to read additional identity-threatening information. According to a Confirmatory Factor Analysis, the three types of information preferences (threatening, bolstering, and distractor/neutral) did not overlap. ${ }^{2}$

AMANOVA was then conducted with condition a fixed factor (identity${ }^{2}$ The initial model was a good fit for the data, $X^{2}(24)=34.06, p=.084, C F I=.979, R M S E A=.042$ (90\% CI: $.000, .071)$, and $S R M R=.039$. The identity-bolstering information preferences included three indicators: positive 1 excerpt $(\lambda=.652, p<.001)$, positive 2 excerpt $(\lambda=.620, p<.001)$, and positive 3 excerpt $(\lambda=.739, p<.001)$. The identity-threatening information preferences included three indicators: negative 1 excerpt $(\lambda=.618, p<.001)$, negative 2 excerpt $(\lambda=.699, p<.001)$, and negative 3 excerpt $(\lambda=.668, p<.001)$. The distractor information included three indicators: distractor 1 excerpt $(\lambda=.558, p<.001)$, distractor 2 excerpt $(\lambda=.735, p<.001)$, and distractor 3 excerpt $(\lambda=.494, p<.001)$. 
threatening article condition vs. neutral article condition) and the two types of information preferences (threatening and bolstering) as dependent variables. The $M A N O V A$ did not indicate a significant multivariate effect on information preferences, Pillai's Trace $(2,240)=.001, p=.92$. In addition, participants who read identity-threatening news articles expressed equivalent desire to read (a) identity-bolstering news stories $(F(1,241)=.12, p=.73)$ and (b) identity-threatening news stories $(F(1,241)=.13, p=.72)$ as those in the neutral article condition (see Table 1). So, H3a and H3bwere not supported.

RQ1 asked if bias-induced anger and anxiety mediated the effect of participants' perceived bias upon participants' subsequent information preferences. We tested for mediating effects of emotion on information preferences by using article bias perceptions as the independent variable (i.e., direct effects) and anger and anxiety as two parallel mediators using Hayes' PROCESS Model 4 (Hayes, 2013). The dependent variables across two models tested were the two types of information preferences: bolstering and threatening. Data only from those in the identity-threatening article conditions were analyzed in these tests.

1) Model testing subsequent identity-bolstering information preferences

As can be seen in Figure 1, participants who perceived more bias felt more anger and anxiety. Participants who felt more anger were less interested in reading additional identity-bolstering news excerpts $(b=-2.52)$, and participants who felt more anxious were more interested in reading additional identity-bolstering news excerpts $(b=1.91)$. However, bias-corrected bootstrap confidence intervals for the indirect effect of bias perceptions via anger $(a b=-.164 ;-.5198$ to .0108$)$ and anxiety ( $a b=.148 ;-.0566$ to .5864$)$ based on 10,000 bootstrap samples both included zero. Therefore, no mediation effect of anger or anxiety on identity-bolstering information preference was detected. Also, no direct effect of perceived bias on subsequent identity-bolstering information seeking was detected $(b=.48$, $p=.489)$.

2) Model testing subsequent identity-threatening information preferences

As can be seen in Figure 2, participants who perceived more bias felt more anger and anxiety. Participants who felt more angry were more interested in reading additional identity-threatening news excerpts $(b=4.22)$, and participants who felt more anxiety were less interested in reading additional identitythreatening news excerpts $(b=-1.07)$. A bias-corrected bootstrap confidence

Table 1. MANOVA analysis of ID-threatening vs. neutral comparison for information preferences.

\begin{tabular}{|c|c|c|c|c|c|c|c|c|}
\hline \multirow{2}{*}{$\begin{array}{c}\text { Dependent } \\
\text { Variables }\end{array}$} & \multirow[b]{2}{*}{$d f$} & \multirow{2}{*}{$\begin{array}{c}d f \\
\text { Error }\end{array}$} & \multirow[b]{2}{*}{$F$} & \multirow[b]{2}{*}{$p$-Value } & \multirow{2}{*}{$\begin{array}{l}\text { News Story } \\
\text { Condition }\end{array}$} & \multirow[b]{2}{*}{$M$} & \multicolumn{2}{|c|}{ 95\% Confidence Interval } \\
\hline & & & & & & & $\begin{array}{l}\text { Lower } \\
\text { Bound }\end{array}$ & Upper Bound \\
\hline \multirow{2}{*}{$\begin{array}{l}\text { ID-bolstering } \\
\text { preference }\end{array}$} & \multirow{2}{*}{1} & \multirow{2}{*}{241} & \multirow{2}{*}{.12} & \multirow{2}{*}{$=.73$} & ID-threatening & 49.73 & 46.79 & 52.68 \\
\hline & & & & & Control & 51.13 & 43.82 & 58.43 \\
\hline \multirow{2}{*}{$\begin{array}{c}\text { ID-threatening } \\
\text { preference }\end{array}$} & \multirow{2}{*}{1} & \multirow{2}{*}{241} & \multirow{2}{*}{.13} & \multirow{2}{*}{$=.72$} & ID-threatening & 52.37 & 49.36 & 55.38 \\
\hline & & & & & Control & 53.82 & 46.36 & 61.29 \\
\hline
\end{tabular}




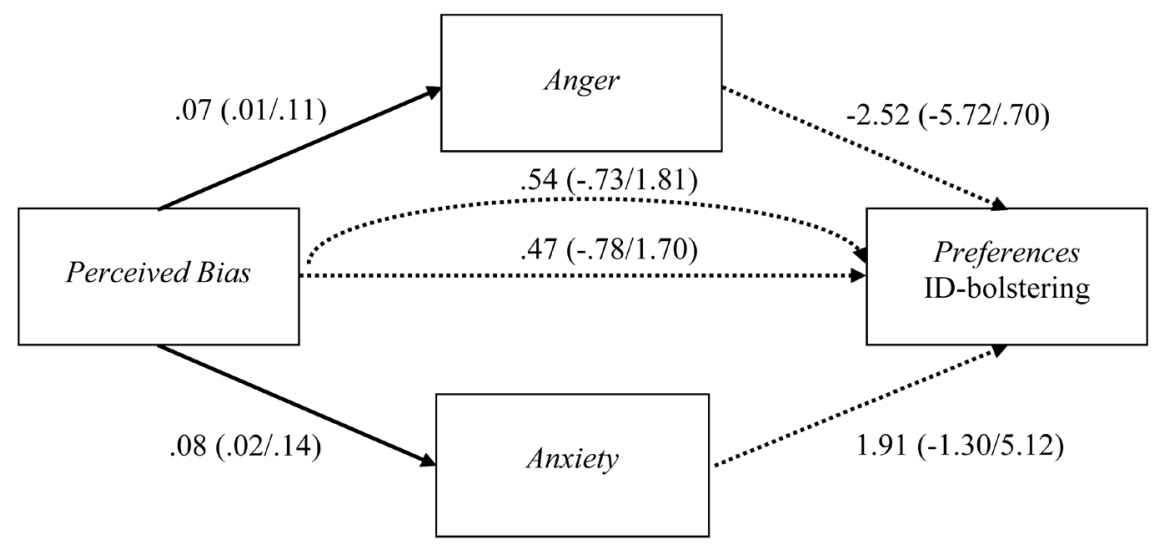

Figure 1. Two parallel mediators model (anger and anxiety) for identity-bolstering information preferences. Note: all coefficients are unstandardized, 95\% bias corrected confidence intervals based on 10,000 bootstrap samples are in parentheses. $\mathrm{N}=243 . \mathrm{R}^{2}=.01$ for full model predicting identity-bolstering information preferences. Solid lines indicate significant relationships. The straight line from perceived bias to identity-bolstering information preferences (c path) represents the direct effect of perceived bias on identitybolstering information seeking, whereas the curved line represents the effect of perceived bias on identity-bolstering information seeking while controlling for the mediation through anger and anxiety.

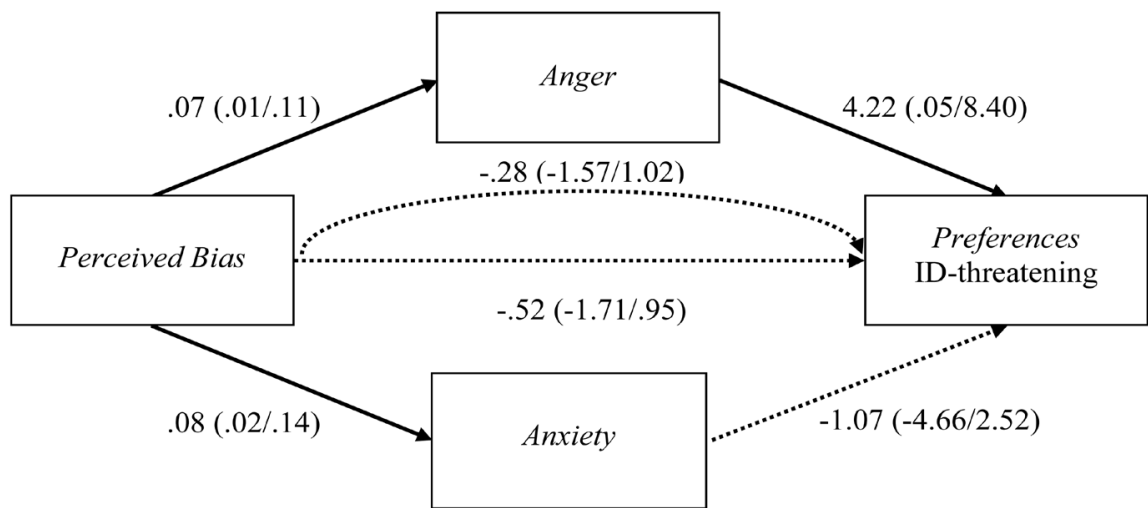

Figure 2. Two parallel mediators model (anger and anxiety) for identity-threatening information preferences. Note: all coefficients are unstandardized, 95\% bias corrected confidence intervals based on 10,000 bootstrap samples are in parentheses. $\mathrm{N}=243 . \mathrm{R}^{2}=.03$ for full model predicting identity-threatening information preferences. Solid lines indicate significant relationships. The straight line from perceived bias to identity-threatening information preferences (c path) represents the direct effect of perceived bias on identity-threatening information seeking, whereas the curved line represents the effect of perceived bias on identity-threatening information seeking while controlling for the mediation through anger and anxiety.

interval for the indirect effect of bias perceptions via anger $(a b=.275 ; .0271$ to .7870$)$ was above zero, but for anxiety $(a b=-.083$; -.4813 to .1547$)$ included zero, based on 10,000 bootstrap samples. Therefore, anger had a mediating effect on subsequent identity-threatening information seeking, but anxiety did not. Also, no direct effect of perceived bias on subsequent identity-threatening information seeking was detected $(b=-.52, p=.472)$. 
To summarize the two mediation analyses testing RQ1, perceived bias indirectly affected only subsequent identity-threatening information preferences through anger. In other words, participants who felt more anger indicated greater interest in additional identity-threatening news excerpts, suggesting that anger might motivate participants to approach in-congenial information. As for anxiety, were no mediation effects were identified.

$\mathrm{H} 4$ hypothesized that novel, identity-threatening issues would elicit more (a) perceived bias (b), anger, and (c) anxiety than familiar, identity-threatening issues. A one-way MANOVA compared responses among those who read novel-issue articles to those who read familiar-issue articles. The results from MANOVA analysis showed a significant multivariate effect, Pillai's Trace $(3,205)=.100, p$ $<.001$. It also showed a significant univariate effect on perceived bias and anger, but not on anxiety (see Table 2). Those who read news articles about novel issues perceived more bias than those who read news articles about familiar issues. Those who read news articles about novel issues felt more anger than those who read news articles about familiar issues. However, those who read about novel issues did not feel more anxious than those who read about familiar issues. Therefore, $\mathrm{H} 4 \mathrm{a}$ and $\mathrm{H} 4 \mathrm{~b}$ were supported. $\mathrm{H} 4 \mathrm{c}$ was not supported.

RQ2 asked if perceived novelty would moderate the proposed mediating effects of bias-induced anger and bias-induced anxiety on subsequent information preferences (both identity-threatening information and identity-bolstering information). The test of RQ1 found mediating effects of bias-induced anger, but not anxiety, on only one form of additional information preference: identity-threatening information. Accordingly, the test of RQ2 examines only whether perceived novelty moderated the single, significant mediating effect identified in RQ1.

To test RQ2, we examined the conditional indirect effect of perceived bias on identity-threatening information preferences via anger using Hayes' PROCESS Model 8 (Hayes, 2013). The conditional indirect effects and inferential tests, computed by using the computational tool described in Hayes (2013), can be found in Figure 3 and Table 3.

Among those who rated the articles as relatively low in perceived novelty, there was no evidence that perceived bias indirectly affected subsequent identity-threatening information preferences through anger; however, among those

Table 2. Univariate effects for issue novelty on perceived bias, anger, and anxiety.

\begin{tabular}{|c|c|c|c|c|c|c|c|c|}
\hline $\begin{array}{l}\text { Dependent } \\
\text { Variables }\end{array}$ & $d f$ & $d f$ error & $F$ & $p$-Value & $\eta^{2}$ & Issue Novelty & $M$ & $S D$ \\
\hline \multirow{2}{*}{ Perceived bias } & \multirow{2}{*}{1} & \multirow{2}{*}{207} & \multirow{2}{*}{19.06} & \multirow{2}{*}{$<.001$} & \multirow{2}{*}{.08} & Novel & 6.27 & 2.20 \\
\hline & & & & & & Familiar & 4.88 & 2.11 \\
\hline \multirow{3}{*}{ Anger } & \multirow{3}{*}{1} & \multirow{3}{*}{207} & \multirow{3}{*}{5.49} & \multirow[b]{2}{*}{$<.05$} & \multirow[b]{2}{*}{.03} & Novel & 1.73 & 1.00 \\
\hline & & & & & & Familiar & 1.40 & .75 \\
\hline & & & & \multirow[b]{2}{*}{$=.23$} & \multirow[b]{2}{*}{-} & Novel & 2.04 & 1.10 \\
\hline Anxiety & 1 & 207 & 1.48 & & & Familiar & 1.85 & .99 \\
\hline
\end{tabular}


Table 3. Results of conditional process model (novelty as moderator and anger as mediator).

\begin{tabular}{|c|c|c|c|c|c|}
\hline \multirow{2}{*}{\multicolumn{2}{|c|}{$\begin{array}{c}\text { Moderator } \\
\text { Novelty }\end{array}$}} & \multirow{3}{*}{$\begin{array}{c}\text { Indirect Effect } \\
M \text { ANGER } \\
-.2494\end{array}$} & \multirow{3}{*}{$\begin{array}{c}S E \\
.2310\end{array}$} & \multicolumn{2}{|c|}{ 95\% Confidence Interval } \\
\hline & & & & \multirow{2}{*}{$\begin{array}{r}\text { Lower } \\
-.9317\end{array}$} & \multirow{2}{*}{$\begin{array}{l}\text { Upper } \\
.0258\end{array}$} \\
\hline $10^{\text {th }}$ percentile & -2.9444 & & & & \\
\hline $25^{\text {th }}$ percentile & -1.6944 & -.0657 & .1309 & -.4590 & .1079 \\
\hline Mean & .0556 & .1915 & .1383 & .0007 & .5747 \\
\hline $75^{\text {th }}$ percentile & 1.5556 & .4120 & .2642 & .0082 & 1.0606 \\
\hline $90^{\text {th }}$ percentile & 2.5556 & .5589 & .3587 & .0113 & 1.4306 \\
\hline
\end{tabular}

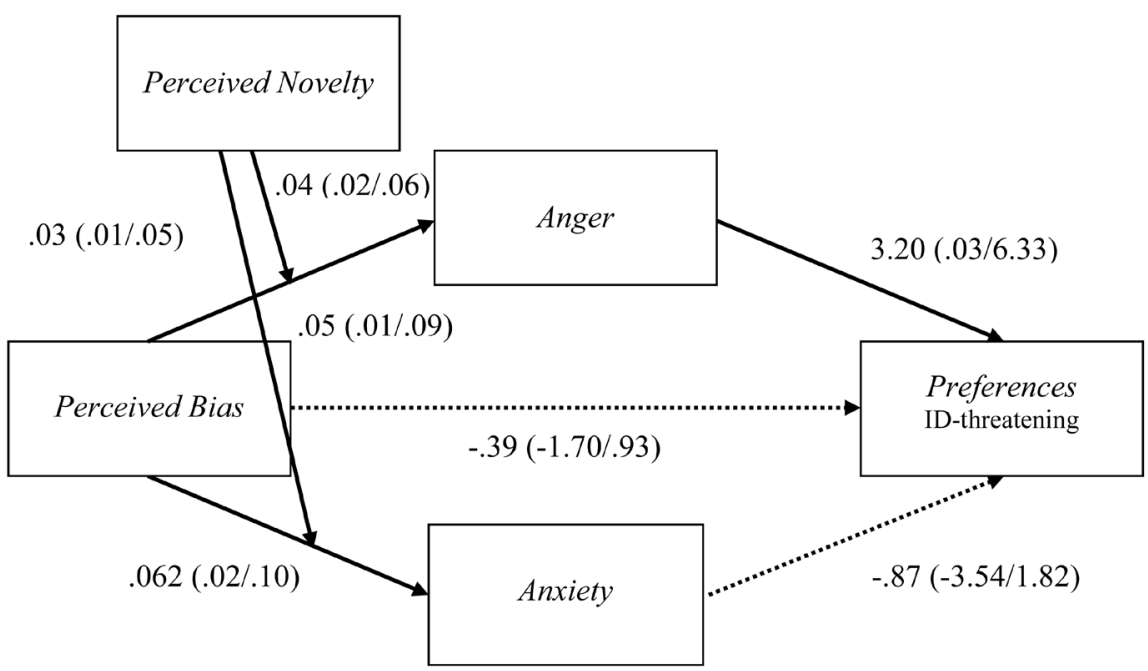

Figure 3. Moderated mediation for anger and anxiety as parallel mediators, and perceived novelty as a moderator. Note: all coefficients are unstandardized, $95 \%$ bias corrected confidence intervals based on 10,000 bootstrap samples are in parentheses. $\mathrm{N}=243 . \mathrm{R}^{2}=.03$ for full model predicting identity-threatening information preferences. Solid lines indicate significant relationships. The line from perceived bias to identity-threatening information preferences (c path) represents the direct effect of perceived bias on identity-threatening information seeking while controlling for the mediation through anger and anxiety. The interaction effects between bias and novelty was significant predictor of anger and anxiety, $\mathrm{b}=.04[.02, .06]$ and $\mathrm{b}=.03[.01, .05]$, respectively.

with average or relatively high perceptions of novelty, the indirect effect was positive and statistically different from zero. In other words, among those who rated the article as moderate to high in novelty, perceived bias was positively associated with subsequent identity-threatening information preferences via increased anger.

\section{Discussion}

Others have suggested that charges of news bias can be accompanied by discrete emotions and our findings supported this prediction: participants who read an identity-threatening news article felt more anger and were more anxious than those who read a neutral news article. Also, perceived bias was correlated with both an- 
ger and anxiety in the threatening-article conditions. We predicted that exposure to threatening news would motivate people to prefer both identity-bolstering information and identity-threatening information (because of bias-induced anger and anxiety), but the tests of $\mathrm{H} 3 \mathrm{a} \& \mathrm{H} 3 \mathrm{~b}$ did not support this proposition. However, the tests of mediation for RQ1 provided evidence that bias-induced anger motivated subsequent identity-threatening information seeking and suggest that it is the extent of anger induced by exposure to news perceived as biased that stimulates interest in additional information rather than exposure itself. Accordingly, individual differences in tendency to respond to threatening information with anger may be of interest in future studies.

The findings of our mediation analyses differ from previous studies. First, the results were not in line with the traditional selective exposure hypothesis-the idea that individuals should prefer identity-bolstering information. Second, the findings also differ from the proposition that anxiety would encourage but anger would shut off subsequent information seeking (Valentino et al. 2008). Rather, our findings add to a growing number of studies that identify a positive relationship between anger and enhanced seeking of information.

In light of these differences, a few possibilities can be considered. First, individuals' assessments of whether they can refute the information challenging their group reputation (i.e., college students) might moderate the effects on congeniality bias/preference for pro-attitudinal information. If individuals consider themselves incapable of refuting identity-threatening information they may be "more motivated to proactively guard against such threats" (Hart et al., 2009: p. 558), and seek more congenial information. However, if our participants had relatively high levels of confidence in the reputation of college students, then congenial information seeking (i.e., identity-bolstering preference) would not be enhanced after reading an identity-threatening news article. Unfortunately, we did not measure such confidence.

Second, perceived information utility and quality of subsequent information choices were neither measured nor controlled in the current study. Congeniality biases might be smaller when subsequent information choices are considered less useful (in terms of a defense motivation) or low in quality (Hart et al., 2009).

With respect to the lack of any mediating effects of anxiety, one explanation is a combination of the stimulus articles and the strength of partisanship among participants. The identity-threatening articles targeted the partisan group of college students. Although our participants were college students, and they clearly felt threatened by the negative stories (as evidenced by elevated bias perceptions, anger, and anxiety in the stimulus versus control conditions), they did not seem to feel highly threatened: both anger and anxiety levels were at the low end of the scale in the threatening article conditions. This could be because they don't identify particularly strongly as college students in general and so were not extremely threatened by the information, or because the articles were not particularly hostile toward their group. In short, although they felt some anxiety, they 
might not have felt that their attitudes or way of life were in sufficient danger to necessitate information seeking for reassurance or reconsideration of their group identity. Further, their group affiliation was, by large degree, involuntary (unlike political party affiliation). Therefore, additional information for the purposes of reconsidering attitudes and affiliation might not have been particularly useful in this case. However, the mediating effect of anger on interest in additional threatening information does suggest that even low levels of discrete anger induced by threatening news can influence information preferences. We suggest future studies include a measure of partisanship to test for moderating effects, use a group for which partisans have a strong, but voluntary affiliation, and/or examine effects of news content that is more threatening to partisans.

The fact that anger mediated the influence of bias perceptions on preference for additional, identity-threatening news suggests anger's action tendency of "approach" enhanced individuals' goals for information preferences. Perhaps this is because the approach tendency of anger is an impulse that offers an incentive. Mediation effects of anger might have manifest because rejecting challenges from identity-threatening information is "emotionally rewarding". Individuals can actively "engage in either counterargument or a search for ways to discount or ignore the offending information", rather than just accepting the negative emotional state, when irritated by counter-attitudinal information (Garrett et al., 2013: p. 116).

As for the effect of perceived novelty, novel issues did elicit more anger than familiar issues. The current study also found anger's mediating effects were stronger when the perceived novelty of the information was relatively high. This finding suggests that people would be more interested in viewing additional counter-attitudinal or identity-threatening information when the threatening information is new to them. When the information is novel, identity-threatening news articles may motivate people to read additional, threatening information regardless of whether their goal is to defend their own view or re-evaluate their position; stories about familiar issues might not encourage people to re/consider the other side of the issue, because they might have all the information they need to defend themselves.

Of note, evidence shows that novelty can evoke feelings of surprise and interest, two discrete emotions that can also prompt exploration, information seeking, and learning (Silvia, 2009). Future research may include interest and surprise as well to examine the interaction between those emotions and anger on information seeking.

Although novel issues did motivate angry participants to look for additional identity-threatening information, familiar issues seemed to merely make angry participants less interested in additional identity-threatening information, and somewhat less interested in additional identity-bolstering information. The avoidance tendency in the familiar issue condition seems to be consistent with findings of a prior study (Valentino et al., 2008) and could explain why that study found no mediating effects of anger: participants were exposed to a familiar issue (Kerry 
vs. Bush) to elicit anger responses in the second experiment.

\section{Conclusion}

The news media are crucial to democracies for the surveillance function and for offering audiences diverse information, because development of relatively accurate beliefs requires citizens to receive some information that may challenge their existing beliefs and opinions (Frey, 1986; Hart et al., 2009; Resnick et al., 2013). Traditional selective exposure research has suggested that people with strong existing opinions might avoid exposure to counter-attitudinal information (Frey, 1986); however, people may prefer counter-attitudinal information if it provides some other utility, such as information quality (Garrett \& Resnick, 2011), and a successful rejection of the challenge from counter-attitudinal information can be considered emotionally rewarding (Garrett et al., 2013). Motivations, either cognitive or affective, are important to the interpretation of the mixed evidence of selective exposure (Hart et al., 2009; Taber \& Lodge, 2006; Garrett et al., 2013).

We found that bias-induced anger did motivate people to prefer additional identity-threatening news information. The implication of this finding in the Internet era is important because people no longer rely on offline news media gate keeping; instead, they rely on search engines, social network sites, news aggregators, and feed ranking algorithms, which provide more selectivity (Resnick, Garrett, Kriplean, Munson, \& Stroud, 2013). The goals for those angry individuals to find more in-congenial news information after they experience perceived bias from a news article might be many. Motivation to look for additional threatening information helps us view the other side; further, anger, as an "approach" emotion (Carver \& Harmon-Jones, 2009) often motivates people to engage in social justice movements, political activities, or change existing views when the threatening information provides new or intriguing perspectives. Our finding that novel issues moderated the mediating effect of bias-induced anger on motivation to view additional identity-threatening information also seems to be in line with this observation.

This study does have its limitations. The first and the most obvious one was the manipulation of novelty/familiar and biased (identity-threatening) news content. The first familiar, identity-threatening news article was designed to be a familiar issue; instead, it was perceived as a novel issue. This indeed reduced the sample size for pooled familiar news article conditions. Although it did not affect subsequent analysis, because the perceived novelty was measured and was able to be statistically controlled, it might have lowered the power to detect the effect of perceived novelty's effect on subsequent information seeking. Also, the third familiar identity-threatening news article was expected to be associated with more perceived bias than the neutral news article did; however, the perceived bias was not statistically higher in the third familiar identity-threatening news article condition than that in the neutral news article condition. Again, although it did not affect subsequent analysis because the perceived bias was also measured and able 
to be statistically controlled, it might have lowered the power to detect the effect of perceived novelty's effect on subsequent information seeking. Second, although the self-reported emotional responses are typical measurement of emotional state, some participants might not be able to readily identify and report their subjective feelings, and therefore, the current study might not be able to identify the full emotional experiences of the participants. Third, the reported state anger was relatively low in terms of the seven-point scale and this might have affected the mediation analysis; however, with the bootstrapping method, the current study still found mediating effects of anger on subsequent information preferences.

Although many are concerned about whether selective exposure will intensify political polarization, there is evidence that likeminded media use can promote higher rates of political participation (Stroud, 2011). Those who feel bias-induced anger and still view the other side's position may be those who have the motivation and ability to engage in attitudinal defense, which is beneficial to democracy and better than a dysfunctional objectivity (Taber \& Lodge, 2006). Future research may focus on the influence discrete emotions (e.g., anger, anxiety, or fear) in the process of information seeking and explore such emotionally rewarding effects.

\section{References}

Arpan, L. M., \& Nabi, R. L. (2011). Exploring Anger in the Hostile Media Process: Effects on News Preferences and Source Evaluation. Journalism and Mass Communication Quarterly, 88, 5-22. https://doi.org/10.1177/107769901108800101

Bennett, W. L., \& Iyengar, S. (2008). A New Era of Minimal Effects? The Changing Foundations of Political Communication. Journal of Communication, 58, 707-731. https://doi.org/10.1111/j.1460-2466.2008.00410.x

Bennett, W. L., \& Iyengar, S. (2010). The Shifting Foundations of Political Communication: Responding to a Defense of the Media Effects Paradigm. Journal of Communication, 60, 35-39. https://doi.org/10.1111/j.1460-2466.2009.01471.x

Brader, T. (2011). The Political Relevance of Emotions: "Reassessing” Revisited. Political Psychology, 32, 337-346. https://doi.org/10.1111/j.1467-9221.2010.00803.x

Brader, T., \& Valentino, N. A. (2007). Identities, Interests and Emotions: Symbolic versus Material Wellsprings of Fear, Anger, and Enthusiasm. In W. R. Neuman, G. E. Marcus, A. Criegler, \& M. MacKuen (Eds.), The Affect Effect. Dynamics of Emotion in Political Thinking and Behavior. Chicago: University of Chicago Press. https://doi.org/10.7208/chicago/9780226574431.003.0008

Brader, T., Valentino, N. A., \& Suhay, E. (2004). Seeing versus Feeling Threats: Group Cues, Emotions, and Activating Opposition to Immigration. In Annual Meeting of the Midwest Political Science Association.

Brader, T., Valentino, N. A., \& Suhay, E. (2008). What Triggers Public Opposition to Immigration? Anxiety, Group Cues, and Immigration Threat. American Journal of Political Science, 52, 959-978. https://doi.org/10.1111/j.1540-5907.2008.00353.x

Carver, C. S., \& Harmon-Jones, E. (2009). Anger Is an Approach-Related Affect: Evidence and Implications. Psychological Bulletin, 135, 183-204. https://doi.org/10.1037/a0013965

Clark, L. A., Watson, D., \& Mineka, S. (1994). Temperament, Personality, and the Mood and Anxiety Disorders. Journal of Abnormal Psychology, 103, 103. https://doi.org/10.1037/0021-843X.103.1.103 
Damasio, A. R. (1994). Descartes' Error. Emotion, Reason, and the Human Brain. New York, NY: Putnam.

Frey, D. (1986). Recent Research on Selective Exposure to Information. Advances in EXperimental Social Psychology, 19, 41-80. https://doi.org/10.1016/S0065-2601(08)60212-9

Garrett, R. K., \& Resnick, P. (2011). Resisting Political Fragmentation on the Internet. Daedalus, 140, 108-120. https://doi.org/10.1162/DAED_a_00118

Garrett, R. K., Carnahan, D., \& Lynch, E. K. (2013). A Turn toward Avoidance? Selective Exposure to Online Political Information, 2004-2008. Political Behavior, 35, 113-134. https://doi.org/10.1007/s11109-011-9185-6

Groenendyk, E. (2011). Current Emotion Research in Political Science: How Emotions Help Democracy Overcome Its Collective Action Problem. Emotion Review, 3, 455-463. https://doi.org/10.1177/1754073911410746

Gunther, A. C. (1998). The Persuasive Press Inference Effects of Mass Media on Perceived Public Opinion. Communication Research, 25, 486-504.

https://doi.org/10.1177/009365098025005002

Gunther, A. C., \& Liebhart, J. L. (2006). Broad Reach or Biased Source? Decomposing the Hostile Media Effect. Journal of Communication, 56, 449-466. https://doi.org/10.1111/j.1460-2466.2006.00295.x

Gunther, A. C., \& Schmitt, K. (2004). Mapping Boundaries of the Hostile Media Effect. Journal of Communication, 54, 55-70. https://doi.org/10.1111/j.1460-2466.2004.tb02613.x

Han, G. K., Chock, T. M., \& Shoemaker, P. J. (2009). Issue Familiarity and Framing Effects of Online Campaign Coverage: Event Perception, Issue Attitudes, and the 2004 Presidential Election in Taiwan. Journalism \& Mass Communication Quarterly, 86, 739-755. https://doi.org/10.1177/107769900908600402

Han, Y. (2014). Might Blaming the News Media Be Beneficial to Democracy? The Effects of Biasinduced Anger, Anxiety, and Issue Novelty on Subsequent News Selection. Doctoral Dissertation, THE Florida State University.

Hart, W., Albarracín, D., Eagly, A. H., Brechan, I., Lindberg, M. J., \& Merrill, L. (2009). Feeling Validated versus Being Correct: A Meta-Analysis of Selective Exposure to Information. Psychological Bulletin, 135, 555-588. https://doi.org/10.1037/a0015701

Hayes, A. F. (2013). Introduction to Mediation, Moderation, and Conditional Process Analysis: A Regression-Based Approach. Guilford Press.

Holbert, R. L., Garrett, R. K., \& Gleason, L. S. (2010). A New Era of Minimal Effects? A Response to Bennett and Iyengar. Journal of Communication, 60, 15-34. https://doi.org/10.1111/j.1460-2466.2009.01470.x

Huddy, L., Feldman, S., \& Cassese, E. (2007). On the Distinct Political Effects of Anxiety and Anger. In W. R. Neuman, G. E. Marcus, A. Criegler, \& M. MacKuen (Eds.), The Affect Effect. Dynamics of Emotion in Political Thinking and Behavior (pp. 202-230). Chicago: University of Chicago Press. https://doi.org/10.7208/chicago/9780226574431.003.0009

Huge, M., \& Glynn, C. J. (2010). Hostile Media and the Campaign Trail: Perceived Media Bias in the Race for Governor. Journal of Communication, 60, 165-181. https://doi.org/10.1111/j.1460-2466.2009.01473.x

Hwang, H., Pan, Z., \& Sun, Y. (2008). Influence of Hostile Media Perception on Willingness to Engage in Discursive Activities: An Examination of Mediating Role of Media Indignation. Media Psychology, 11, 76-97. https://doi.org/10.1080/15213260701813454 
Isbell, L., Ottati, V., \& Burns, K. (2006). Affect and Politics: Effects on Judgement, Processing and Information Seeking. In D. P. Redlawsk (Ed.), Feeling Politics. Emotion in Political Information Processing (pp. 57-86), New York, NY: Palgrave Macmillan. https://doi.org/10.1057/9781403983114_5

Kiss, Z. (2012). Habit or Reasoned Decision? Electoral Campaigns and the Effect of Emotions on Vote Choice. 2012 APSA Annual Meeting, New Orleans.

Ladd, J. M., \& Lenz, G. S. (2008). Reassessing the Role of Anxiety in Vote Choice. Political Psychology, 29, 275-296. https://doi.org/10.1111/j.1467-9221.2008.00626.x

Lawrence, E., Sides, J., \& Farrell, H. (2010). Self-Segregation or Deliberation? Blog Readership, Participation, and Polarization in American Politics. Perspectives on Politics, 8, 141-157. https://doi.org/10.1017/S1537592709992714

Lazarus, R. S. (1991). Emotion and Adaptation. New York, NY: Oxford University Press.

LeDoux, J. E. (1996). The Emotional Brain: The Mysterious Underpinnings of Emotional Life. New York, NY: Simon \& Schuster.

Lee, T. (2010). Why They Don't Trust the Media: An Examination of Factors Predicting Trust. American Behavioral Scientist, 54, 8-21. https://doi.org/10.1177/0002764210376308

Lord, C. G., Ross, L., \& Lepper, M. R. (1979). Biased Assimilation and Attitude Polarization: The Effects of Prior Theories on Subsequently Considered Evidence. Journal of Personality and Social Psychology, 37, 2098-2109.

https://doi.org/10.1037/0022-3514.37.11.2098

MacKuen, M., Wolak, J., Keele, L., \& Marcus, G. E. (2010). Civic Engagements: Resolute Partisanship or Reflective Deliberation. American Journal of Political Science, 54, 440-458. https://doi.org/10.1111/j.1540-5907.2010.00440.x

Marcus, G. E. (2002). The Sentimental Citizen: Emotion in Democratic Politics. University Park, PA: Pennsylvania State University Press.

Marcus, G. E., Neuman, W. R., \& MacKuen, M. (2000). Affective Intelligence and Political Judgement. Chicago, IL: Chicago University Press.

Matthes, J. (2011). Exposure to Counterattitudinal News Coverage and the Timing of Voting Decisions. Communication Research, 39, 147-169.

https://doi.org/10.1177/0093650211402322

Mutz, D. C. (2006). Hearing the Other Side: Deliberative Versus Participatory Democracy. Cambridge: Cambridge University Press. https://doi.org/10.1017/CBO9780511617201

Nabi, R. L. (2002). Anger, Fear, Uncertainty, and Attitudes: A Test of the Cognitive-Functional Model. Communication Monographs, 69, 204-216. https://doi.org/10.1080/03637750216541

Nabi, R. L. (2010). The Case for Emphasizing Discrete Emotions in Communication Research. Communication Monographs, 77, 153-159. https://doi.org/10.1080/03637751003790444

Pew Research Center for the People and the Press (2006). Maturing Internet News Audience Broader than Deep: Online Papers Modestly Boost Newspaper Readership. http://www.people-press.org/2006/07/30/online-papers-modestly-boost-newspaper-rea dership/

Pew Research Center for the People and the Press (2012a). Trends in News Consumption: 1991-2012.

http://www.people-press.org/2012/09/27/in-changing-news-landscape-even-televisionis-vulnerable/ 
Pew Research Center for the People and the Press (2012b). Trends in American Values: 1987-2012: Partisan Polarization Surges in Bush, Obama Years.

http://www.people-press.org/2012/06/04/partisan-polarization-surges-in-bush-obamayears/

Resnick, P., Garrett, R. K., Kriplean, T., Munson, S. A., \& Stroud, N. J. (2013). Bursting Your (Filter) Bubble: Strategies for Promoting Diverse Exposure. In Proceedings of the 2013 Conference on Computer Supported Cooperative Work Companion (pp. 95-100). New York, NY: ACM. https://doi.org/10.1145/2441955.2441981

Sawicki, V., Wegener, D. T., Clark, J. K., Fabrigar, L. R., Smith, S. M., \& Bengal, S. T. (2011). Seeking Confirmation in Times of Doubt: Selective Exposure and the Motivational Strength of Weak Attitudes. Social Psychology and Personality Science, 2, 540-546. https://doi.org/10.1177/1948550611400212

Shoemaker, P. J. (1996). Hardwired for News: Using Biological and Cultural Evolution to Explain the Surveillance Function. Journal of Communication, 46, 32-47.

Silvia, P. J. (2009). Looking Past Pleasure: Anger, Confusion, Disgust, Pride, Surprise, and Other Unusual Aesthetic Emotions. Psychology of Aesthetics, Creativity, and the Arts, 3, 48-51. https://doi.org/10.1037/a0014632

Smith, S. M., Fabrigar, L. R., \& Norris, M. E. (2008). Reflecting on Six Decades of Selective Exposure Research: Progress, Challenges, and Opportunities. Social and Personality Psychology Compass, 2, 464-493. https://doi.org/10.1111/j.1751-9004.2007.00060.x

Steenbergen, M., \& Ellis, C. (2006). Fear and Loathing in American Elections: Context, Traits, and Negative Candidate Affect. In D. P. Redlawsk (Ed.), Feeling Politics. Emotion in Political Information Processing. New York, NY: Palgrave Macmillan. https://doi.org/10.1057/9781403983114_7

Stroud, N. J. (2011). Niche News. The Politics of News Choice. New York, NY: Oxford University Press. https://doi.org/10.1093/acprof:oso/9780199755509.001.0001

Taber, C. S., \& Lodge, M. (2006). Motivated Skepticism in the Evaluation of Political Beliefs. American Journal of Political Science, 50, 755-769. https://doi.org/10.1111/j.1540-5907.2006.00214.x

Tajfel, H., \& Turner, J. C. (1985) The Social Identity Theory of Intergroup Behavior. In S. Worchel, \& W. G. Austin (Eds.), Psychology of Intergroup Relations (pp. 7-24). Chicago: Nelson-Hall.

Tsfati, Y., \& Cappella, J. N. (2003). Do People Watch What They Do Not Trust? Exploring the Association between News Media Skepticism and Exposure. Communication Research, 30, 504-529. https://doi.org/10.1177/0093650203253371

Valentino, N. A., Banks, A. J., Hutchings, V. L., \& Davis, A. K. (2009). Selective Exposure in the Internet Age: The Interaction between Anxiety and Information. Political Psychology, 30, 591-613. https://doi.org/10.1111/j.1467-9221.2009.00716.x

Valentino, N. A., Hutchings, V. H., Banks, A. J., \& Davis, A. K. (2008). Is a Worried Citizen a Good Citizen? Emotions, Political Information Seeking, and Learning via the Internet. Political Psychology, 29, 247-273.

https://doi.org/10.1111/j.1467-9221.2008.00625.x 